\title{
Evaluation of the effect of Irritrol as final irrigant against Staphylococcus epidermidis: an in Vitro Study
}

\begin{abstract}
Hezha Saadi Hassan ${ }^{(1)}$; Diyar Khalid Bakr ${ }^{(2)}$
Background and Objective: Endodontic infections are considered to be caused by the presence of various microorganisms within the root canal system. Staphylococcus epidermidis is one of the most isolated or detected species from oral infections, including marginal periodontitis, infected root canals, peri-radicular, peri-implantitis, and also detected in cases of failed endodontic therapy. In order to prevent endodontic treatment, failure irrigation is mandatory for the effective removal of smear, pulp tissue, smear layer, and microorganisms. The objective of the current study is to evaluate and compare the effect of Irritrol with other final irrigants regarding disinfecting root canal from S. epidermidis.
\end{abstract}

Methods: Fifty-five single roots premolars with single canals were selected. All of the samples were infected with standard strains of Staphylococcus Epidermidis. Samples were randomly divided into five groups, and five teeth were put as a control group to be compared to the samples after disinfection. Each group consisted of 10 samples according to the type of final irrigants used during and after instrumentation: $5.25 \% \mathrm{NaOCl} /$ Irritrol as final irrigant G2 NaOCl 5.25\% / NaOCl 5.25\%, G3 Normal Saline, G4 Irritrol with activation, $\mathrm{G} 5 \mathrm{NaOCl}$ with activation. All samples were prepared and instrumented by using ProTaper NEXT rotary system till X3. $5.25 \% \mathrm{NaOCl}$ was applied with a $27-\mathrm{G}$ double side-vented syringe needle as an initial irrigant then followed by the final irrigants. Ultra $X$ ultrasonic device was used for the activation of irrigation with a high degree of 45,000 kHz and using tip size $20 \#$ with taper of $2 \%$. CFU of each sample was counted before irrigation regime and after the irrigation regime, and they were compared to the control group.

Results: In decreasing the amount of bacteria colonies G4 (Irritol with activation) $94 \%$ and G5 ( $\mathrm{NaOCl} 5.25 \%), 92 \%$ of the CFU were decreased compared to the control group. Whereas, in Group 3 (Normal Saline) had the least effect on the CFU count decrease. In group 1 (Irritrol) and G2 without activation. Irritrol had less effect than $\mathrm{NaOCl} 5.25 \%$ in the amount of eliminating bacteria count.

Conclusion: Irritrol, $\mathrm{NaOCl} 5.25 \%$ with the aid of PUI, can eliminate a significant amount of bacteria in the root canal. In the future, irritrol might be able to be a promising antibacterial irrigant as well as a chelating agent.

Keywords: Irritrol, antibacterial, Staphylococcus epidermidis, disinfection.

\footnotetext{
${ }^{(1)}$ Department of Conservative Dentistry, College of Dentistry, Tishik International University, Erbil, Iraq.

${ }^{(2)}$ Department of Conservative Dentistry, College of Dentistry, Hawler Medical University, Erbil, Iraq. Correspondent Name: -HezahSaadi Hassan

Email:hezhasindi@gmail.com
}

\section{Introduction}

The leading cause of periapical and pulp pathology is bacteria and its byproducts. Root canal treatment is removing the source of infection by eliminating microbes and necrotic tissues in the root canal system. Aim of root canal treatment is to decrease the number of microorganisms, tissue debris, inorganic debris, closing the space and prevent recontamination by filling materials. A crucial part of successful root canal treatment is irrigation as it fulfills many important chemical, mechanical, and microbiological functions. Irrigation is the only way to compensate for the unreachable areas in the root canal systems. ${ }^{1}$ 
Irrigants should have antimicrobial activity, also, be able to dissolve organic matter, have low toxicity on the surrounding tissue. ${ }^{2}$ One of the most common irrigation regimens that are used is sodium hypochlorite $(\mathrm{NaOCl})$, which has a broad-spectrum antiseptic effect. Also, it can dissolve vital as well as necrotic tissue. ${ }^{3}$ Chlorhexidine Gluconate (CHX) is irrigation that is frequently used in root canal disinfection for having a broadspectrum antimicrobial effect, and relatively low cytotoxicity. ${ }^{4}$ But, in some studies, it is shown that $\mathrm{CHX}$ does not dissolve pulp tissue. ${ }^{5,6}$ However, using files for root canal shaping creates a smear layer which contains inorganic dentin debris, organic substances containing odontoblastic process, microorganisms, microbes associated with the infection, and necrotic pulp tissue and this smear layer could be removed by ethylenediaminetetraacetic acid (EDTA). For facilitating irrigation of the root canals and decreasing the steps of the irrigation. New material was produced, which contains a combination of two or more materials. Such as Q-mix (Dentsply Tulsa Dental Specialties, Tulsa, OK, USA) Has the combination of $17 \%$ EDTA and Chlorhexidine. This solution can dissolve inorganic matter and have antibacterial capacity. ${ }^{7}$ Every now and then, new material is being invented to decrease the steps and be more efficient in root canal treatment. Irritrol is a two in one irrigation (Essential Dental Systems, USA) which have been developed to be an endodontic irrigant that used for smear layer removal and antibacterial activity. It has a clear greenish color. It contains EDTA (Ethylenediaminetetraacetic acid) and chlorhexidine. ${ }^{8}$

S. Epidermidis is a microflora skin that is a commensal organism, which it usually has a benign relationship with the host. Although it is also ranked as one of the first nosocomial and implant-based infections, it might be because of its ubiquity on the skin. ${ }^{9}$ However, Staphylococci are not a usual species in the oral cavity, some species such as staphylococcus epidermidis have been found in saliva samples from healthy individuals. $S$. Epidermidis has also been isolated from oral infectious diseases such as periimplantitis, root surface caries, severe marginal periodontitis. Root canal infections and refractory marginal periodontitis. ${ }^{10}$ S. Epidermidis is one of the common prevalent bacteria amongst persistent endodontic infection is Staphylococcus epidermidis which has well-equipped genes that provide protection against harsh conditions encountered in its natural habitat. ${ }^{11}$

For an irrigation solution to reach most of the unreachable areas in the complex anatomy of the canal, auxiliary canals, inorganic and organic debris accumulation, and isthmuses activation of the irrigation is needed which will promote the effectiveness of smear layer removal and reaching the irrigation to the deeper parts of the canal. ${ }^{12}$ Also, an apical vapor lock is created during root canal irrigation procedure with positive pressure using syringe irrigation. This vapor lock creates air bubble in the canal. Which significantly obstructs irrigant solution to reach the apical third of the root canal space. By activating the irrigant, this vapor lock will be avoided. $^{13}$ Ultra X ( Eighteeth, Changzhou Sifary Medical Technology, China) is a cordless ultrasonic activator, easy to use and it has the frequency of $(45,000 \mathrm{~Hz})$ which is enough to create an acoustical stream and to be effective in disrupting biofilm, clean, reduce bacteria levels, remove vapor lock, and improving penetration of irrigant. There are limited studies regarding the comparison between Irritrol and $\mathrm{NaOCl}$. Also, this study is about the evaluation of the activation of irritrol and $\mathrm{NaOCl}$ for killing bacteria.

\section{Methods}

Fifty-five human premolar extracted teeth that have single canals were selected to use in this study. Those teeth had been freshly 
extracted for orthodontic reasons. The inclusion criterion for those samples is to have mature and straight roots. Moreover, the exclusion criterion of those teeth that had variation in the canal anatomy, presence of microcracks, fractures, resorption, previous endodontically treated tooth, calcification, and curved canals. Those samples were cleaned from calculus and soft tissue residual by periodontal scaler and polished by polishing paste. Then they were stored in distilled water to avoid dehydration and kept in a cooling refrigerator to be used later on in this study. Each sample was decoronated to have a length of $12 \mathrm{~mm}$ from the anatomic apex, by using a diamond disk and electronic caliper for measuring the length. Then, a file $10 \mathrm{k}$-file was used to confirm the patency of the canals. And the working length was set to $11 \mathrm{~mm}$ after the extrusion of the file tip beyond the apical foramen. ${ }^{14}$ After confirmation of the working length of each sample. The foramen enlarged to $\mathrm{k}$ file \#15 to have a standardized foramen prior to shaping the canals using Protaper Next files. Then they were sealed from the apex with red wax ( Polywax Toughened dental modeling wax, Bilkim company, Turkey) to avoid extrusion of the irrigant through the apical foramen and to mimic natural conditions of the presence of periapical tissues during chemo-mechanical instrumentation. ${ }^{15}$ For holding the samples, custom molds were made by using a plastic water pipe, which was prepared to $(20 \mathrm{~mm}$ length- diameter of $25.4 \mathrm{~mm}$, which equals one-inch pipe diameter), and samples were put in putty silicone impression material. The silicon impression molded in the pipe prepared earlier to establish a standardized position and orientation of canal preparation. Samples were divided into four groups randomly based on the final irrigation that would be used later on. Those molds were fixed to a table by using a table jack that was fixed to the table. Each group randomly contained ten teeth. All the teeth and their corresponding pipe were coded; they were fixed to the table jack. Each of the samples was instrumented by \# $15 \mathrm{~K}$-file and reached to \# $20 \mathrm{~K}$-file (Dentsply maillefer) to have a standardized foramen before using rotary files. Instrumentation and shaping of all samples started using ProTaper Next nickeltitanium (Dentsply Maillefer; Ballaigues, Switzerland) rotary system by a sequence of X1, X2 and X3 at $300 \mathrm{rpm}$ and $3.5 \mathrm{Ncm}$ according to manufacturer's instructions. After each ProTaper NEXT rotary file sequence recapitulation were done by using a $10 \#$ K-file. Also, irrigation solution applied between each endodontic rotary file by using $2 \mathrm{ml}$ of $5.25 \% \mathrm{NaOCl}$ (Chlora XiD, Cerkamed, Poland ) with a $27-\mathrm{G}$ Double side-vented endodontic irrigation needle. The syringe was placed $1 \mathrm{~mm}$ short of the working length. ${ }^{16}$ After finishing instrumentation, all the samples were dried by paper point and put in sterilized pouches, and they were sterilized using autoclave 1.5 bar for 45 minutes.

Standard strains of Staphylococcus epidermidis ATC 12228 purchased and confirmed by Vitek 2 (bioMérieux, Inc, Hazelwood, Mo). After isolation, a single colony of S. epidermidis from 24-48 hours culture was selected and inoculated in Brain Heart Infusion (BHI) this was allowed to be inoculated for 48 hours at $37^{\circ}$ $\mathrm{C}$ in an incubator. Serial dilution was done after incubation to be able to decrease the concentration of bacteria to obtain desired colony forming unit (CFU)/ $\mathrm{ml}$ per plate. A serial dilution was performed until 1/10000 is reached. Each sample was infected with ten $\mu \mathrm{L}$ prepared $S$. epidermidis by using a sterile micropipette, and they were incubated for 48 hours at $37^{\circ} \mathrm{C}$. After incubation, a swap was taken for the control group and cultured on blood agar plate to be compared later with the samples that will undergo disinfection procedure. ${ }^{17}$ Samples were divided into five groups randomly, and each group was irrigated by $4 \mathrm{ml}$ of one of the following final rinses ${ }^{18}$. 1) Irritol 2) $\mathrm{NaOCl} 5.25$ 3) Normal Saline 4) Irritol + activation 5) $\mathrm{NaOCl}+$ activation. 
Experimental group that did not receive activation, were irrigated by $4 \mathrm{ml}$ of the final solution, and the experimental group that will receive activation was rinsed by $2 \mathrm{ml}$ then activated for 30 seconds by ultra $\mathrm{x}$ ultrasonic activator with the tip size of $20 \#$ and 2\% taperness ( Eighteeth, Changzhou Sifary Medical Technology, China) in an up and down gentle motion $2 \mathrm{~mm}$ away from the apical constriction as mentioned by the manufacturer and then again rinsed with 2 $\mathrm{ml}$ which total of $4 \mathrm{ml}$. Swaps by paper point were taken from each sample by inserting the paper-point $11 \mathrm{~mm}$ into the canals that have undergone the irrigation and placed the swap on Blood agar plates and incubated for 48 hours and the temperature of $37^{\circ} \mathrm{C}$. After two days of incubation, the CFU was counted under the colony counter and compared with the control group. The sample groups were as follows.

Control group: 5 teeth were infected with the bacteria and considered as positive control group

Group 1: Ten teeth, those samples were infected and irrigated by $4 \mathrm{~mL}$ irritrol ( Essential Dental Systems, USA). Double side vented $27 \mathrm{G}$ needle $2 \mathrm{~mm}$ short of the working length with gentle pressure for 1 $\min$.

Group 2: Ten teeth, those samples were infected and irrigated by $4 \mathrm{ml} \mathrm{NaOCl} \%$ 5.25

( Chlora XiD, Cerkamed, Poland ). Dou- ble side vented $27 \mathrm{G}$ needle $2 \mathrm{~mm}$ short of the working length with gentle pressure for $1 \mathrm{~min}$.

Group 3: Ten teeth, those samples were infected and irrigated by $4 \mathrm{ml}$ Normal Saline $0.9 \%$. Double side vented $27 \mathrm{G}$ needle 2 $\mathrm{mm}$ short of the working length with gentle pressure for $1 \mathrm{~min}$.

Group 4: Ten teeth, those samples were infected and irrigated by $4 \mathrm{ml}$ of Irritrol. Two $\mathrm{ml}$ were used by using double sided $27 \mathrm{G}$ needle $2 \mathrm{~mm}$ short to working length and activated by using Ultra x ( Eighteeth, Changzhou Sifary Medical Technology, China) for 30 seconds, then another $2 \mathrm{ml}$ irritrol were used as final rinse.

Group 5: Ten teeth, those samples were infected and irrigated by $4 \mathrm{ml}$ of $\mathrm{NaOCl} \%$ 5.25. Two $\mathrm{ml}$ were used by using double sided $27 \mathrm{G}$ needle $2 \mathrm{~mm}$ short to working length and activated by using Ultra $\mathrm{x}$ ( Eighteeth, Changzhou Sifary Medical Technology, China) for 30 seconds, then another $2 \mathrm{ml} \mathrm{NaOCl} 5.25 \%$ were used as final rinse

After irrigation, swaps by paper point were taken from each sample that have undergone the irrigation and placed the swap on Blood agar plates and incubated for 48 hours and the temperature of $37{ }^{\circ} \mathrm{C}$. After two days of incubation, the CFU were counted under the colony counter device and compared with the control group.

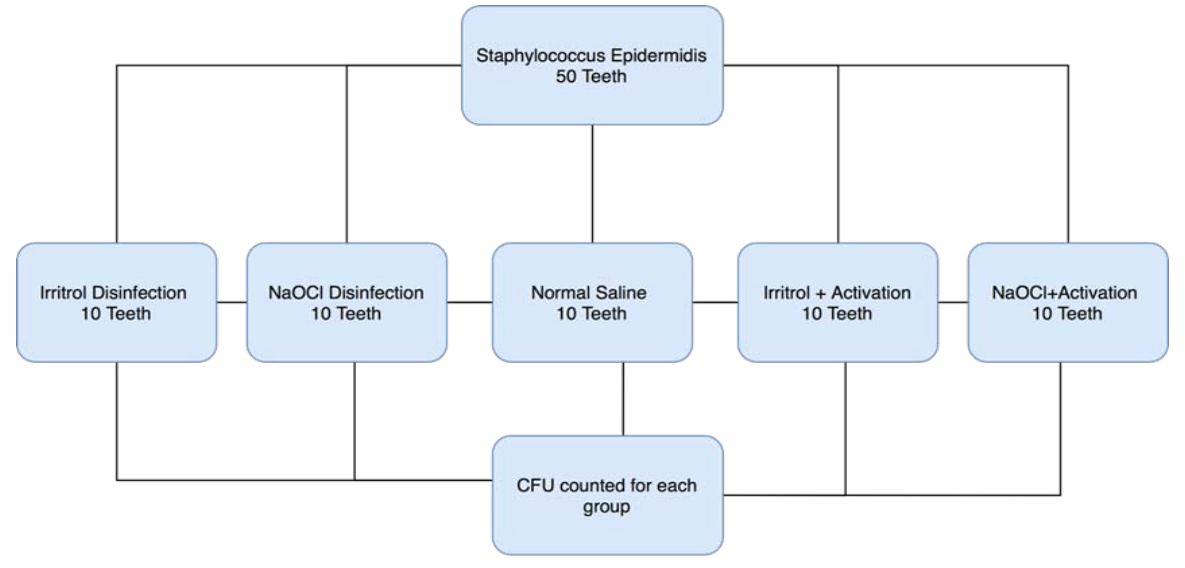

Figure1: A schematic diagram showing sample grouping 
Statistical analysis: Statistical analysis. The statistical analysis was performed using the SPSS software package (Version 23). Descriptive analysis for the sample, mean and standard deviation were calculated and using Shapiro-wilk, Oneway ANOVA were used. The level of statistical significance was set at $\mathrm{p}<0.05$.

\section{Results}

In this study, the control group CFU/ml was $700 \times 10^{6}$ before other samples underwent irrigation. For the data in this study, descriptive statistics of mean and standard deviation values were used for viable and dead bacteria, and also percentage was used as in (Table 1).

Table 1: mean values for alive and \% mean for dead bacteria.

\begin{tabular}{|c|c|c|c|}
\hline & $\mathbf{N}$ & Alive (Mean \pm SD) & Dead (Mean\% SD\%) \\
\hline Irritrol & 10 & 10 & $61 \% \pm 8 \%$ \\
\hline NaOCl & 10 & 10 & $81 \% \pm 6 \%$ \\
\hline Normal Saline & 10 & 10 & $13 \% \pm 7 \%$ \\
\hline Irritrol+activation & 10 & 10 & $94 \% \pm 6 \%$ \\
\hline NaOCl+ activation & 10 & 10 & $92 \% \pm 13 \%$ \\
\hline
\end{tabular}

In the descriptive data Group 4 has the In Figure 2, a graph showed the percentage lowest mean value of $42 \times 10^{7}$ and Group 3 of each group. Group 4, the percentage has has the highest mean value of $606 \times 10^{7}$. the highest value of $94 \%$, and for the lowest There are no significant differences in mean value in the groups is group 3 with $13 \%$. value between group 4 (Irritrol + Activation) Group 4 94\% and group $592 \%$, there is no and group $5(\mathrm{NaOCl} 5.25 \%+$ Activation). significant difference in the percentage While there is significant differences values. In group 1, 61\%, and group 2, 81\%, a between group 1 (Irritrol) and group 2 significant difference regarding the decrease $(\mathrm{NaOCl} 5.25 \%)$ as shown in table 1 . in the bacterial count can be seen here.

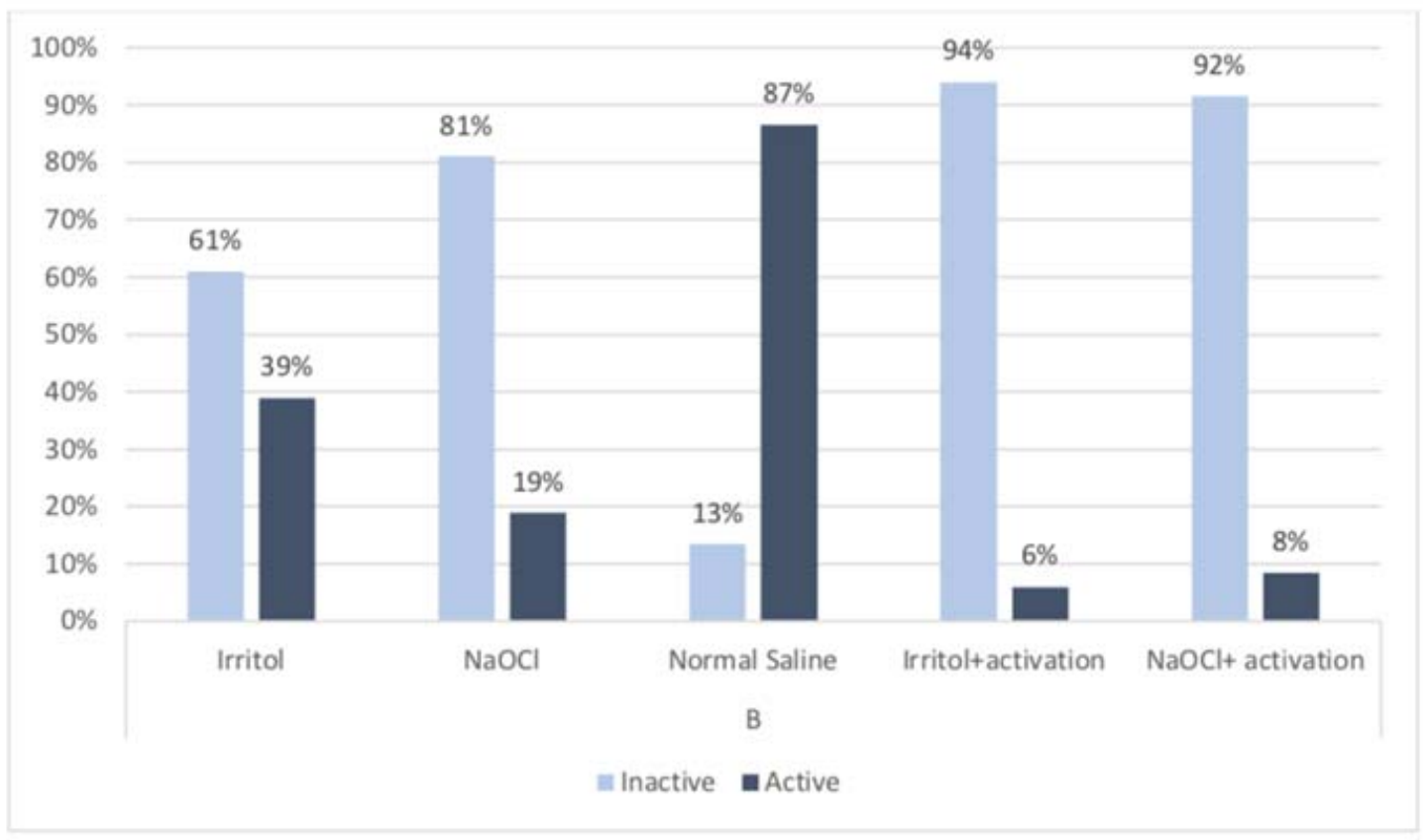

Figure 2: Percentage of inactive bacteria colonies and viable active bacteria colonies. 
In (table 2) we can see normality test for data distribution that is conducted for each group, and mostly all of them can be seen underlying normal distribution due to having $\mathrm{p}$-values higher than 0.05 (The null hypothesis says the data is normally distributed, is accepted).

In the above section, we saw significant gaps between the mean values of the materials regarding the remaining active bacteria colonies. Nevertheless, it could not prove that whether the differences are statistically significant or not, since more than two groups are in this study, assuming that the variance of the data is the same for all groups, thus, we can go head to implement One way ANOVA as in to discover the difference between mean value of the materials for each group. In this study dissimilar result received from ANOVA test there was difference in mean value of the materials and using Tukey test we reached to say that no statistically significant difference has occurred between G2 and G5, G4 with G5 It is worth mentioning that statistically, significant difference existed between G2 and G4 along with the others as seen in (Table 3 ).

Table 2: Shapiro-wilk for normality of data distribution

\begin{tabular}{|c|c|c|c|}
\hline \multirow{2}{*}{ Technique } & Shapiro-Wilk & Shapiro-Wilk & Shapiro-Wilk \\
\cline { 2 - 4 } & Statistic & df & P-Value \\
\hline Irritrol & 0.939 & 10 & 0.575 \\
\hline NaOCl & 0.921 & 10 & 0.366 \\
\hline Normal Saline & 0.989 & 10 & 0.995 \\
\hline Irritrol+activation & 0.897 & 10 & 0.204 \\
\hline NaOCl+ activation & 0.698 & 10 & 0.001 \\
\hline
\end{tabular}

Table 3: One way ANOVA to discover the difference between mean and value of the groups.

\begin{tabular}{|c|c|c|c|c|c|c|}
\hline \multicolumn{2}{|c|}{ Main Group } & $\begin{array}{c}\text { Sum of } \\
\text { Squares }\end{array}$ & df & $\begin{array}{c}\text { Mean } \\
\text { Square }\end{array}$ & F & $\begin{array}{c}\text { P- } \\
\text { Value }\end{array}$ \\
\hline & $\begin{array}{c}\text { Between } \\
\text { Groups }\end{array}$ & 2168095.720 & 4 & 542023.930 & \multirow{2}{*}{161.496} & 0.000 \\
\cline { 2 - 6 } & Within Groups & 151031.800 & 45 & 3356.262 & & \\
\cline { 2 - 5 } & Total & 2319127.520 & 49 & & \\
\cline { 2 - 5 } $\begin{array}{c}\text { Tukey Pairwise compari- } \\
\text { son }\end{array}$ & \multicolumn{7}{|c|}{ - No difference between G2and G5 } \\
\hline
\end{tabular}

\section{Discussion}

In the current study, irritrol has been used to compare with $\mathrm{NaOCl}$ regarding antibacterial ability. Three final irrigants were used in this study ( Irritrol, $\mathrm{NaOCl}$ $5.25 \%$, Normal saline). The final irrigation procedure was performed using a $27-\mathrm{G}$ double side vented endodontic needle and activated using ultra $\mathrm{X}$ wireless ultrasonic technology and its ability to generate $(40,000 \mathrm{~Hz})$, which is required to create sufficient acoustical streaming. Irritrol is an irrigant consists of both CHX and EDTA. As we know, chlorhexidine is an effective antibacterial. Another advantage of this irrigant is that it is two in one, which reduces the steps of irrigation regarding chelating and disinfection procedure. The presence of a surfactant in irritrol makes it reduce its tension, which leads to better removal of the smear layer. ${ }^{19}$ Regarding penetration of irrigation solution into dentinal tubules in a study that is done by Küçük and Kermeoğlu, 2019. ${ }^{8}$ Has shown that irritrol has a similar capability in penetrating dentinal tubules as Q-mix and CHX.

Sodium hypochlorite is a potent 
antibacterial and one of the most used irrigation solution to disinfect root canal against bacteria and dissolve organic tissue. In this study using $\mathrm{NaOCl} 5.25 \%$ by positive pressure technique results were comparable to $\mathrm{CHX}$ in killing bacteria this result agree with. ${ }^{20-22}$ Also, results of this study disagree with previous studies ${ }^{23,24}$ Which it has been reported that there is no significant difference between two materials regarding killing bacteria.

Passive ultrasonic irrigation (PUI) is a critical step in the regime of root canal irrigation. To have a greater effect of disinfection than syringe irrigation, activation of irrigation is needed. By activating the irrigation in the canal will have results in eliminating pulp tissue and dentin debris. Which in contrast, ultrasonic creates a faster flow volume of the irrigant into the root canal during irrigation; thus, this results in better removing debris and smear layer, less apical packing, and improving the reaching of the chemical products to accessory canals and isthmuses. Which, in the end, results in the better killing of bacteria than syringe irrigation. ${ }^{25}$ Results obtained by this study showed that activation of $\mathrm{NaOCl}$ and Irritrol had a great effect on decreasing the number of bacteria. While positive pressure technique had less effect on decreasing bacterial count. Those results agree with previous studies. ${ }^{26,27}$ Results in the present study disagree with the results of a prior study done by Forghani et al. ${ }^{28}$ Which reported that using passive sonic activation had no benefit compared to regular needle irrigation. Irritrol with PUI showed slightly better results than $\mathrm{NaOCl}$ with PUI; this might be due to the ability of Irritrol as a chelating agent since it contains EDTA that removes the smear layer, which, this enables irrigation to penetrate deeper in dentinal tubules. ${ }^{8}$

Staphylococcus Epidermidis was used as experimental bacteria in the present study as this bacteria species is considered one of the most persistent bacteria species that cause secondary infection in root canal failures after Enterococcus faecalis. ${ }^{11}$ A secondary intra radicular infections might happen because of microorganisms that were not present in the primary infection and might have penetrated the root canal system during treatment, between appointment sessions, or after finishing of the endodontic treatment. Also, secondary infection might occur due to the contamination of instruments used in root canal procedures during root canal treatment, microleakage of the restoration, remnants of dental plaque, caries or calculus on the tooth crown, rubber dam leakage, or contamination of irrigant solutions or other solutions f o r i n t r a c a n a 1 u s e. Since S.epidermidis presents in the air or oral cavity, it will be relevant for contamination to happen. ${ }^{10}$

Colony forming unit (CFU) is a quantitative method is a method to measure the amount of viable bacteria on a culture plate. ${ }^{29}$ In this study, CFU/ ml method was used to evaluate the amount of bacteria reduction after irrigation comparing to before irrigation procedure. Comparison of CFU/ $\mathrm{ml}$ before and after irrigation in this study shows that using normal saline as final irrigation has minimal effect on decreasing number of colonies that might be due flushing effect of normal saline. ${ }^{30}$ While Irritrol with activation and $\mathrm{NaOCl}$ with activation had the greatest amount of CFU reduction in this study and the result agrees with previous studies. ${ }^{31,32}$

\section{Conclusion}

Based on the results obtained from this study, Irritrol, $\mathrm{NaOCl} 5.25 \%$ are all antibacterial agents with the aid of PUI, both materials were able to eliminate the maximum amount of bacteria in the root canal. There were no significant difference in group 4 and 5, while, there was a significant difference in group 1 and 2 . Irritrol might be a promising antibacterial, a chelating agent in the future. However, further investigation is required to find the 
efficacy of Irritrol as a root canal disinfection agent.

\section{Conflict of interest}

The author reported no conflict of interests.

\section{References}

1. Haapasalo M, Shen Y, Wang Z, Gao Y. Irrigation in endodontics. Br Dent J. 2014 Mar;216(6):299303.

2. Vivacqua-Gomes N, Ferraz CCR, Gomes BPFA, Zaia AA, Teixeira FB, Souza-Filho FJ. Influence of irrigants on the coronal microleakage of laterally condensed gutta-percha root fillings. Int Endod J. 2002 Sep;35(9):791-5.

3. Zhang K, Kim YK, Cadenaro M, Bryan TE, Sidow SJ, Loushine RJ, et al. Effects of different exposure times and concentrations of sodium hypochlorite/ethylenediaminetetraacetic acid on the structural integrity of mineralized dentin. J Endod. 2010 Jan;36(1):105-9.

4. Mohammadi Z, Abbott PV. The properties and applications of chlorhexidine in endodontics. Int Endod J. 2009 Apr;42(4):288-302.

5. Naenni N, Thoma K, Zehnder M. Soft tissue dissolution capacity of currently used and potential endodontic irrigants. J Endod. 2004 Nov;30 (11):785-7.

6. Okino LA, Siqueira EL, Santos M, Bombana AC, Figueiredo $\mathrm{J}$ a. P. Dissolution of pulp tissue by aqueous solution of chlorhexidine digluconate and chlorhexidine digluconate gel. Int Endod J. 2004 Jan;37(1):38-41.

7. Arslan D, Guneser MB, Kustarci A, Er K, Siso SH Pulp tissue dissolution capacity of QMix 2in1 irrigation solution. Eur J Dent. 2015 Sep;9(3):423 $-7$.

8. Küçük M, Kermeoğlu F. Efficacy of different irrigation methods on dentinal tubule penetration of Chlorhexidine, QMix and Irritrol: A confocal laser scanning microscopy study. Aust Endod J. 2019 Aug;45(2):202-8.

9. Niazi SA, Clarke D, Do T, Gilbert SC, Mannocci F, Beighton D. Propionibacterium acnes and Staphylococcus epidermidis Isolated from Refractory Endodontic Lesions Are Opportunistic Pathogens. Journal of Clinical Microbiology. 2010 Nov 1;48(11):3859-69.

10. Siqueira JF, Lima KC. Staphylococcus epidermidis and Staphylococcus xylosus in a secondary root canal infection with persistent symptoms: a case report. Aust Endod J. 2002 Aug;28(2):61-3.

11. Rogers KL, Fey PD, Rupp ME. Coagulase-negative staphylococcal infections. Infect Dis Clin North Am. 2009 Mar;23(1):73-98.

12. George S, Kishen A, Song KP. The role of environ- mental changes on monospecies biofilm formation on root canal wall by Enterococcus faecalis. J Endod. 2005 Dec;31(12):867-72.

13. Tay FR, Gu L-S, Schoeffel GJ, Wimmer C, Susin L, Zhang $\mathrm{K}$, et al. Effect of vapor lock on root canal debridement by using a side-vented needle for positive-pressure irrigant delivery. J Endod. 2010 Apr;36(4):745-50.

14. Liu Y, Guo L, Li Y, Guo X, Wang B, Wu L. In vitro comparison of antimicrobial effectiveness of QMix and other final irrigants in human root canals. Scientific Reports [Internet]. 2015 [cited 2019 Mar 24];5. Available from: https:// www.ncbi.nlm.nih.gov/pmc/articles/ PMC4668572/

15. Niu L, Luo X, Li G, Bortoluzzi EA, Mao J, Chen J, et al. Effects of different sonic activation protocols on debridement efficacy in teeth with singlerooted canals. J Dent. 2014 Aug;42(8):1001-9.

16. Di Fiore PM, Genov KA, Komaroff E, Li Y, Lin L. Nickel-titanium rotary instrument fracture: a clinical practice assessment. Int Endod J. 2006 Sep;39(9):700-8.

17. Das SC, Kapoor KN. Effect of growth medium on hydrophobicity of Staphylococcus epidermidis. Indian J Med Res. 2004 Mar;119(3):107-9.

18. Mahdi SF, Bakr DK. Evaluation of the effect of SmearOFF on Smear Layer Removal and Erosion of Root Canal Dentin. Erbil Dental Journal (EDJ). 2019 Dec 6;2(2):269-77.

19. Agrawal R, Purayil TP, Ballal NV, Belle VS. Comparative evaluation of postobturation apical seal following intracanal irrigation with maleic acid or a combination of chlorhexidine and ethylenediaminetetraacetic acid: An in vitro study. Saudi Endodontic Journal. 2018 Jan 1;8(1):34.

20. Zehnder M. Root canal irrigants. J Endod. 2006 May;32(5):389-98.

21. Ayhan H, Sultan N, Cirak M, Ruhi MZ, Bodur H. Antimicrobial effects of various endodontic irrigants on selected microorganisms. Int Endod J. 1999 Mar;32(2):99-102.

22. Ringel AM, Patterson SS, Newton CW, Miller $\mathrm{CH}$, Mulhern JM. In vivo evaluation of chlorhexidine gluconate solution and sodium hypochlorite solution as root canal irrigants. J Endod. 1982 May;8(5):200-4.

23. Siqueira JF, Rôças IN, Santos SRLD, Lima KC, Magalhães FAC, de Uzeda M. Efficacy of instrumentation techniques and irrigation regimens in reducing the bacterial population within root canals. J Endod. 2002 Mar;28(3):181-4.

24. Rôças IN, Siqueira JF. Comparison of the in vivo antimicrobial effectiveness of sodium hypochlorite and chlorhexidine used as root canal irrigants: a molecular microbiology study. J Endod. 2011 Feb;37(2):143-50. 
25. van der Sluis LWM, Gambarini G, Wu MK, Wesselink PR. The influence of volume, type of irrigant and flushing method on removing artificially placed dentine debris from the apical root canal during passive ultrasonic irrigation. Int Endod J. 2006 Jun;39(6):472-6.

26. Nagendrababu V, Jayaraman J, Suresh A, Kalyanasundaram S, Neelakantan P. Effectiveness of ultrasonically activated irrigation on root canal disinfection: a systematic review of in vitro studies. Clin Oral Invest. 2018 Mar 1;22(2):65570.

27. Cohenca N, Silva LAB, Silva RAB, Nelson-Filho $P$, Heilborn C, Watanabe E, et al. Microbiological Evaluation of Different Irrigation Protocols on Root Canal Disinfection in Teeth with Apical Periodontitis: An In Vivo Study. Brazilian Dental Journal. 2013 Oct;24(5):467-73.

28. Forghani M, Afshari E, Parisay I, Garajian R. Effect of a passive sonic irrigation system on elimination of Enterococcus faecalis from root canal systems of primary teeth, using different concentrations of sodium hypochlorite: An in vitro evaluation. J Dent Res Dent Clin Dent Prospects. 2017;11(3):177-82.

29. Wilson C, Lukowicz R, Merchant S, ValquierFlynn H, Caballero J, Sandoval J, et al. Quantita- tive and Qualitative Assessment Methods for Biofilm Growth: A Mini-review. Res Rev J Eng Technol [Internet]. 2017 Dec [cited 2020 Feb 7];6(4). Available from: https:// www.ncbi.nIm.nih.gov/pmc/articles/ PMC6133255/

30. Sabharwal S, Sabharwal S, Bhagat SK, Bhagat SK, Gami KS, Gami KS, et al. An in vivo study to compare anti microbial activity of triantibiotic paste, $2 \%$ chlorhexidine gel, and calcium hydroxide on microorganisms in the root canal of immature teeth. Journal of International Society of Preventive and Community Dentistry. 2019 May 1;9(3):263.

31. Dumani A, Guvenmez HK, Yilmaz S, Yoldas O, Kurklu ZGB. Antibacterial Efficacy of Calcium Hypochlorite with Vibringe Sonic Irrigation System on Enterococcus faecalis: An In Vitro Study [Internet]. BioMed Research International. 2016 [cited 2020 Feb 15]. Available from: https:// w w w. hind a w i. com / journals / bmri/2016/8076131/

32. Hage W, De Moor RJG, Hajj D, Sfeir G, Sarkis DK, Zogheib C. Impact of Different Irrigant Agitation Methods on Bacterial Elimination from Infected Root Canals. Dentistry Journal. 2019 Sep;7 (3):64. 